\title{
Summary of the Mars Science Goals, Objectives, Investigations, and Priorities
}

Mars Exploration Program Analysis Group (MEPAG) Goals Committee:

Don Banfield, Cornell University, (607)351-7818, banfield@astro.cornell.edu

Jennifer Stern, NASA Goddard Space Flight Center

\author{
Alfonso Davila, NASA Ames \\ Sarah Stewart Johnson, Georgetown University \\ David Brain, University of Colorado \\ Robin Wordsworth, Harvard University \\ Briony Horgan, Purdue University \\ Rebecca M.E. Williams, Planetary Science Institute \\ Paul Niles, NASA Johnson Space Center \\ Michelle Rucker, NASA Johnson Space Center \\ Kevin Watts, NASA Johnson Space Center
}

Full Document is available on:

https://mepag.jpl.nasa.gov/reports/MEPAGGoals_2020_MainText_Final.pdf 


\section{INTRODUCTION}

Since 2000, the Mars Exploration Program Analysis Group (MEPAG) has maintained a document entitled "Mars Science Goals, Objectives, Investigations and Priorities" (informally known as the MEPAG Goals Document) as a statement of the Mars exploration community's consensus regarding its scientific priorities for investigations to be carried out by and in support of the robotic Mars flight program. This document has been regularly updated (roughly every 2-3 years) to respond to discoveries made by the missions of the Mars Exploration Program and changes in the strategic direction of NASA. To ensure that the document faithfully represents a community consensus, each revision has sought, received and incorporated broad input from across the Mars community (including results from flight missions, Research and Analysis results, as well as the results of studies sponsored by MEPAG and other bodies), at several levels of the revision process (i.e., from identifying aspects of the document that need revision, to specific comments on draft versions before publication). Because of the breadth and depth of this process, the MEPAG Goals Document represents a strong voice of the community. The most recent full revision of the document was completed March 2020, in preparation for the Planetary Science Decadal Survey.

The MEPAG Goals Document is organized into a four-tiered hierarchy: goals, objectives, sub-objectives and investigations. The Goals are organized around four major areas of scientific knowledge, commonly referred to as Life (Goal I), Climate (Goal II), Geology (Goal III), and Preparation for Human Exploration (Goal IV); expanded statements of the Goals are found in their respective chapters. MEPAG does not prioritize among the four Goals because developing a comprehensive understanding of Mars as a system requires making progress in all three science areas, and because the Goal of preparing for human exploration is different in nature.

Each Goal includes objectives that embody the knowledge, strategies, and milestones needed to achieve the goal. The sub-objectives include more detail and clarity on different parts of objectives, but cover tasks that are larger in scope than individual investigations. The investigations that go into collectively achieving each sub-objective constitute the final tier of the hierarchy (not cataloged below due to space limitations). Although some investigations could be achieved with a single measurement, others require a suite of measurements, some of which require multiple missions.

Each set of investigations is independently prioritized within the parent sub-objective. The priorities have been based on consideration of the following four factors: (1) Status of existing measurements compared to the needed measurements and their accuracy; (2) Relative value of an investigation in achieving a stated objective; (3) Identification of logical sequential relationships; and (4) Cost, risk and feasibility of implementation. In some cases, the specific measurements needed to address an investigation are discussed; however, how those measurements should be made (e.g., via specific instruments or mission concepts) is not specified by the Goals Document, allowing the competitive proposal process to identify the most effective means of making progress towards their realization.

It should be noted that completion of all of the investigations in the MEPAG Goals Document would require decades. Given the complexity involved, it is also possible that they might never be truly complete. In addition, observations answering old questions often raise new questions. Thus, evaluations of prospective instruments and missions should be based on how well investigations are addressed and how much progress might be achieved in the context of that specific instrument or mission. 


\section{INTEGRATING THE MEPAG GOALS TO UNDERSTAND MARS AND BEYOND}

Most of Mars science is, by nature, cross-cutting. For example, geological and mineralogical evidence for long-lived standing bodies of water in the ancient past provides a constraint for climate models. Such interrelationships are what make Mars investigations so compelling within the broader scope of solar system science, but are difficult to appreciate within the hierarchical structure of this Goals document. Thus, in addition to chapters on each of the four Goals, we have also included a final chapter-entitled "Integrating the MEPAG Goals to Understand Mars and Beyond"- to identify and explain the important scientific pursuits that extend across the boundaries of our four Goals. We have organized this chapter using the overarching questions (or "Big Questions") in Planetary Science that the MEPAG community developed in response to a request of the NASA Planetary Science Division Director in 2019. Discussing how our Goals map onto these overarching questions, which span all of planetary science, underscores how the Mars Program contributes to understanding our solar system and planetary systems in general.

\section{GOAL I: DETERMINE IF MARS EVER SUPPORTED, OR STILL SUPPORTS, LIFE}

\begin{tabular}{|l|l|}
\hline \multicolumn{1}{|c|}{ Objectives } & \multicolumn{1}{c|}{ Sub-Objectives } \\
\hline $\begin{array}{l}\text { A. Search for evidence of } \\
\text { life in environments that } \\
\text { have a high potential for } \\
\text { habitability and preserva- } \\
\text { tion of biosignatures. }\end{array}$ & $\begin{array}{c}\text { A1. Determine if signatures of life are present in environments affected by } \\
\text { liquid water activity. }\end{array}$ \\
\cline { 2 - 2 } & $\begin{array}{c}\text { A2. Investigate the nature and duration of habitability near the surface and } \\
\text { in the deep subsurface. }\end{array}$ \\
\cline { 2 - 2 } $\begin{array}{l}\text { A3. Assess the preservation potential of biosignatures near the surface } \\
\text { and with depth }\end{array}$ \\
\hline $\begin{array}{l}\text { B. Assess the extent of } \begin{array}{l}\text { abiotic organic chemical } \\
\text { evolution. }\end{array} \\
\text { B1. Constrain atmospheric and crustal inventories of carbon (particularly } \\
\text { organic molecules) and other biologically important elements over time. }\end{array}$ \\
\cline { 2 - 2 } & $\begin{array}{l}\text { B2. Constrain the surface, atmosphere, and subsurface processes through } \\
\text { which organic molecules could have formed and evolved over martian } \\
\text { history. }\end{array}$ \\
\hline
\end{tabular}

The search for evidence of life beyond Earth remains one of the highest goals in planetary exploration, and the surface and subsurface of Mars are compelling destinations for this pursuit. The general notion that Earth and Mars may have been relatively similar worlds during their early histories, combined with the relatively early emergence of life on Earth, gives rise to the possibility that life could also have emerged and evolved on Mars. The documented history of past habitable conditions on Mars and the discovery of organic matter in sedimentary deposits suggest that signatures of life could be detectable. Current and emerging technologies enable us to evaluate this possibility with scientific rigor.

The implications of a positive detection for either extinct or extant life would be farreaching. Finding life on another world would have great social and scientific impacts, and would undoubtedly motivate a variety of follow-up inquiries to understand how that life functioned or functions, which attributes of biochemistry, structure and physiology are shared with terrestrial life, what mechanisms underlie those attributes that differ, and whether Mars preserves evidence relating to the origin of that life. Discovery of an extant biosphere would also impact the future exploration of Mars with humans (Goal IV).

An apparent negative result (noting that it is not possible to demonstrate definitively that life did not take hold on Mars) will still provide valuable scientific insights regarding the evolution of Mars. For example, a search for evidence of life follows on a search for potentially habitable environments - i.e., environments affected by liquid water activity. Identifying such envi- 
ronments not only informs landing site selection for life detection experiments, but also advances our knowledge of the climatic, geochemical and geologic evolution of Mars. Even if evidence of life is not found in a potentially habitable environment, much can still be learned in the process. For example, a search for organic compounds in a potentially habitable environment could result in the discovery of abiotic organic matter derived from geologic or exogenous sources. This would represent a unique opportunity to investigate abiotic organic chemical evolution in an environment that could sustain life, and a chance to address important questions related to the origin of life: To what extent did Mars develop prebiotic chemistry? Are organic molecules, biological building blocks, present in martian geologic materials? Did abiotic chemical pathways that mimic biological metabolic pathways ever evolve? What processes have been responsible for fixation and transport of biologically important elements such as carbon and nitrogen on ancient and modern Mars? What other evidence for abiotic organic processing exists in the unexplored regions of Mars, including the near and deep subsurface?

In situ investigations addressing Goal I will require access to the martian surface and subsurface. Many of the scientifically interesting sites for life detection and prebiotic chemistry investigations are confined to relatively small areas. This will likely demand higher landing accuracy than what has been achieved in past missions. There might also be a need for surface mobility in order to reach the most compelling sampling sites, or to access different sampling locations. High landing accuracy and a certain degree of surface mobility currently require more resources than traditional Discovery-class missions such as Phoenix and Insight, likely more in line with New Frontiers-class missions. Substantial technology development devoted to making these capabilities for more economical architectures could accelerate advances on Goal I's Objectives.

\section{GOAL II: UNDERSTANDING THE PROCESSES AND HISTORY OF CLIMATE} Objectives Sub-Objectives

A. Characterize the state and controlling processes of the presentday climate of Mars under the current orbital configuration.

B. Characterize the history and controlling processes of Mars' climate in the recent past, under different orbital configurations.

C. Characterize Mars' ancient climate and underlying processes.
A1. Characterize the dynamics, thermal structure, and distributions of dust, water, and carbon dioxide in the lower atmosphere.

A2. Constrain the processes by which volatiles and dust exchange between surface and atmospheric reservoirs.

A3. Characterize the chemistry of the atmosphere and surface

A4. Characterize the state and controlling processes of the upper atmosphere and magnetosphere.

B1: Determine the climate record of the recent past that is expressed in geomorphic, geological, glaciological, and mineralogical features of the polar regions.

B2: Determine the record of the climate of the recent past that is expressed in geomorphic, geological, glaciological, and mineralogical features of low- and mid-latitudes.

B3: Determine how the chemical composition and mass of the atmosphere changed in the recent past.

C1. Determine how the chemical composition and mass of the atmosphere have evolved from the ancient past to the present.

C2. Find and interpret surface records of past climates and factors that affect climate. 
The fundamental scientific questions that underlie Goal II concern how the climate of Mars has evolved over time to reach its current state, and the present and past processes that control climate. This is a subject of intrinsic scientific interest that also has considerable implications for comparative planetology with Earth and other terrestrial planets, in the solar system and beyond. Mars' climate can be defined as the mean state and variability of its atmosphere and exchangeable volatile and aerosol reservoirs, evaluated from diurnal to geologic time scales. For convenience, the climate history of Mars can be divided into three different states: (i) Present climate, operating under the current orbital parameters and observable today; (ii) Recent past (i.e. $<\sim 20 \mathrm{Myr}$ ) climate operating under similar pressures, temperatures, and composition, but over a range of orbital variations (primarily obliquity) that change the pattern of solar radiation on the planet and whose effects are evident in the geologically recent physical record; and (iii) Ancient climate, when the pressure and temperature may have been substantially higher than at present, the atmospheric composition may have been different, and liquid water was likely episodically or continuously stable on the surface.

On Mars, as on Earth, the present holds the key to the past: a comprehensive understanding of the fundamental processes at work in the present climate is necessary to have confidence in conclusions reached about the recent past and ancient climate, when Mars may have been more habitable than today. Because many of the processes that governed the climate of the recent past are likely similar to those that are important today, an understanding of the present climate strongly enhances our confidence in our understanding of the climate in the recent past. Furthermore, since not all climate processes leave a distinctive record, it is also necessary to determine which climate processes may have recorded detectable signatures in the climate archives of the recent past. Numerical models play a critical role in interpreting the recent past and ancient climate, and it is important that they be validated against observations of the present climate in order to provide confidence in results for more ancient climates that are no longer directly observable.

A variety of missions of different sizes could make great progress on investigations related to Martian climate. These could include New Frontiers or Discovery class missions to study the Martian polar regions, land a meteorological network on the surface, return atmospheric samples, or investigate coupling between the lower and upper atmosphere They could also include SmallSat or cubesat missions to provide multi-point magnetospheric observations, or to emplace one or more miniature landers to study in situ meteorology and aeolian processes. Several high priority Goal II investigations could also be addressed by including appropriate instruments on a Mars Sample Return mission.

\section{GOAL III: DETERMINE THE EVOLUTION OF THE SURFACE AND INTERIOR}

\begin{tabular}{|l|l|}
\hline \multicolumn{1}{|c|}{ Objectives } & \multicolumn{1}{c|}{ Sub-Objectives } \\
\hline $\begin{array}{l}\text { A. Document the geologic record } \\
\text { preserved in the crust and investi- } \\
\text { gate the processes that have created } \\
\text { and modified that record. }\end{array}$ & $\begin{array}{l}\text { A1. Identify and characterize past and present water and other } \\
\text { volatile reservoirs. }\end{array}$ \\
\cline { 2 - 2 } & $\begin{array}{c}\text { A2. Document the geologic record preserved in sediments } \\
\text { and sedimentary deposits. }\end{array}$ \\
\cline { 2 - 2 } & $\begin{array}{l}\text { A3. Constrain the magnitude, nature, timing, and origin of an- } \\
\text { cient environmental transitions. }\end{array}$ \\
\cline { 2 - 2 } & $\begin{array}{l}\text { A4. Determine the nature and timing of construction and } \\
\text { modification of the crust. }\end{array}$ \\
\hline B. Determine the structure, composi- & B1. Identify and evaluate manifestations of crust-mantle \\
\hline
\end{tabular}




\begin{tabular}{|l|l|}
\hline tion, and dynamics of the interior $\begin{array}{l}\text { interactions. } \\
\text { and how it has evolved. }\end{array}$ & $\begin{array}{l}\text { B2. Quantitatively constrain the age and processes of accre- } \\
\text { tion, differentiation, and thermal evolution of Mars. }\end{array}$ \\
\hline $\begin{array}{l}\text { C. Determine origin and geologic his- } \\
\text { tory of Mars' moons and implica- } \\
\text { tions for the evolution of Mars. }\end{array}$ & $\begin{array}{l}\text { C1. Constrain the origin of Mars' moons based on their } \\
\text { surface and interior characteristics. }\end{array}$ \\
\cline { 2 - 2 } & $\begin{array}{l}\text { C2. Determine the material and impactor flux within the } \\
\text { Mars neighborhood, throughout martian history, as recorded } \\
\text { on Mars' moons. }\end{array}$ \\
\hline
\end{tabular}

Study of the planet's interior and surface composition, structure, and geologic history is the subject of Goal III. The scope of Goal III is fundamental to understanding the solar system as a whole, as well as providing insight into the geologic evolution of terrestrial planets. The geologic record on Mars is unparalleled in the solar system in the breadth and depth of planetary history that it preserves, and thus provides unique opportunities to understand the evolution of terrestrial planets over time. Habitability and water are a common theme throughout the highest priority investigations in Goal III, but the geologic record of Mars also preserves an equally long record of climatic, volcanic, impact, and interior processes. Goal III investigations have relevance to understanding Earth's early history (much of which is not preserved) and comparative planetology by broadening the range of known geologic behavior on terrestrial planets (including uniquely martian processes).

Many of the higher priority investigations associated with the geology discipline would benefit from Mars sample return (dateable specimen, hydrous history, etc.). Small missions with access to the surface have the capability to address a plethora of Goal III investigations, especially by broadening the number and type of observational opportunities. Highly impactful small mission concepts could include deployment of multi-location surface platforms (e.g., seismic network, in situ active processes monitoring, outcrop-scale observations across a diversity of geologic terrains) and greater accessibility to challenging landing sites (e.g., higher latitudes, rugged terrain, high winds).

\section{GOAL IV: PREPARE FOR HUMAN EXPLORATION}

\begin{tabular}{|c|c|}
\hline Objectives & Sub-Objectives \\
\hline \multirow{3}{*}{$\begin{array}{l}\text { A. Obtain knowledge of Mars } \\
\text { sufficient to design and } \\
\text { implement human landing } \\
\text { at the designated human } \\
\text { landing site with acceptable } \\
\text { cost, risk and performance. }\end{array}$} & $\begin{array}{l}\text { A1. Determine the aspects of the atmospheric state that affect orbital } \\
\text { capture and EDL for human scale missions to Mars. }\end{array}$ \\
\hline & $\begin{array}{l}\text { A2. Characterize the orbital debris environment around Mars with } \\
\text { regard to future human exploration infrastructure. }\end{array}$ \\
\hline & $\begin{array}{l}\text { A3. Assess landing-site characteristics and environment related to } \\
\text { safe landing of human-scale landers. }\end{array}$ \\
\hline \multirow{4}{*}{$\begin{array}{l}\text { B. Obtain knowledge of Mars } \\
\text { sufficient to design and } \\
\text { implement human surface } \\
\text { exploration and EVA on } \\
\text { Mars with acceptable cost, } \\
\text { risk and performance. }\end{array}$} & $\begin{array}{l}\text { B1. Assess risks to crew health \& performance by: (1) characterizing } \\
\text { in detail the ionizing radiation environment at the martian surface \& } \\
\text { (2) determining the possible toxic effects of martian dust on humans. }\end{array}$ \\
\hline & $\begin{array}{l}\text { B2. Characterize the surface particulates that could affect engineering } \\
\text { performance and lifetime of hardware and infrastructure. }\end{array}$ \\
\hline & $\begin{array}{l}\text { B3. Assess the climatological risk of dust storm activity in the human } \\
\text { exploration zone at least one year in advance of landing \& } \\
\text { operations. }\end{array}$ \\
\hline & $\begin{array}{l}\text { B4. Assess landing-site characteristics and environment related to } \\
\text { safe operations and trafficability within the possible area to be } \\
\text { accessed by elements of a human mission. }\end{array}$ \\
\hline
\end{tabular}




\begin{tabular}{|c|c|}
\hline \multirow{2}{*}{$\begin{array}{l}\text { C. Obtain knowledge of Mars } \\
\text { sufficient to design and } \\
\text { implement In Situ Resource } \\
\text { Utilization of atmosphere } \\
\text { and/or water on Mars with } \\
\text { acceptable cost, risk and } \\
\text { performance. }\end{array}$} & $\begin{array}{l}\text { C1. Understand the resilience of atmospheric In Situ Resource } \\
\text { Utilization processing systems to variations in martian near surface } \\
\text { environmental conditions. }\end{array}$ \\
\hline & $\begin{array}{l}\text { C2. Characterize potentially extractable water resources to support } \\
\text { ISRU for long-term human needs. }\end{array}$ \\
\hline \multirow{5}{*}{$\begin{array}{l}\text { D. Obtain knowledge of Mars } \\
\text { sufficient to design and } \\
\text { implement biological } \\
\text { contamination and } \\
\text { planetary protection } \\
\text { protocols to enable human } \\
\text { exploration of Mars with } \\
\text { acceptable cost, risk and } \\
\text { performance. }\end{array}$} & $\begin{array}{l}\text { D1. Determine the martian environmental niches that meet the } \\
\text { definition of "Special Region" at the human landing site and inside of } \\
\text { the exploration zone. }\end{array}$ \\
\hline & $\begin{array}{l}\text { D2. Determine if the martian environments to be contacted by humans } \\
\text { are free, to within acceptable risk standards, of biohazards that } \\
\text { could adversely affect crew members who become directly exposed. }\end{array}$ \\
\hline & $\begin{array}{l}\text { D3. Determine if martian materials or humans exposed to the martian } \\
\text { environment can be certified free, within acceptable risk standards, } \\
\text { of biohazards that might have adverse effects on the terrestrial } \\
\text { environment and species if returned to Earth. }\end{array}$ \\
\hline & $\begin{array}{l}\text { D4. Determine the astrobiological baseline of the human landing site } \\
\text { prior to human arrival. }\end{array}$ \\
\hline & $\begin{array}{l}\text { D5. Determine the survivability of terrestrial organisms exposed to } \\
\text { martian surface conditions to better characterize the risks of forward } \\
\text { contamination to the martian environment. }\end{array}$ \\
\hline \multirow{2}{*}{$\begin{array}{l}\text { E. Obtain knowledge of Mars } \\
\text { sufficient to design and } \\
\text { implement a human } \\
\text { mission to the surface of } \\
\text { either Phobos or Deimos } \\
\text { with acceptable cost, risk, } \\
\text { and performance. }\end{array}$} & $\begin{array}{l}\text { E1. Understand the geological, compositional, and geophysical } \\
\text { properties of Phobos or Deimos sufficient to establish specific } \\
\text { scientfic objectives, operations planning, and any potentially } \\
\text { available resources. }\end{array}$ \\
\hline & $\begin{array}{l}\text { E2. Understand the conditions at the surface and in the low orbital } \\
\text { environment for the martian satellites sufficiently well so as to be } \\
\text { able to design an operations plan, including close proximity and } \\
\text { surface interactions. }\end{array}$ \\
\hline
\end{tabular}

Goal IV encompasses the use of robotic flight missions (to Mars) to prepare for potential human missions (or sets of missions) to the martian system. In broadest context, Mars is a partially unknown place, and our partial or missing knowledge creates risk to the design and implementation of a human mission. Many important risks can be "bought down" and/or efficiencies achieved by means of acquiring precursor information, which allows for betterinformed architectural, design, and operational decisions. In the same way that the Lunar Orbiters, Ranger, and Surveyor landers paved the way for the Apollo Moon landings, the robotic missions of the Mars Exploration Program can continue to help chart the course for potential future human exploration of Mars.

The topic of planetary protection and human exploration continues to be subject to changes and refinements in thinking. We anticipate that this topic will need frequent updating for the forseeable future. We favor human exploration as a means for accomplishing incredible science on Mars and believe that the risks posed by forward contamination are manageable if it is conducted in a responsible manner, perhaps within an "exploration zone" which would contain human activities and might be subject to a different planetary protection policy than one for missions to other parts of the planet. However, that is currently not officially adopted in any NASA policy.

\section{THE FUTURE OF NASA'S MARS PROGRAM}


Mars has a uniquely accessible archive of the long-term evolution of a habitable planet. The planet presents outstanding access to environments fundamental to the search for past and/or present signs of life and offers an unparalleled opportunity to study climate and habitability as an evolving, system-level phenomenon. The Mars Architecture Strategy Working Group (MASWG) concluded that a distinct and identifiable robotic Mars program is necessary to accomplish the compelling and broad-reaching scientific objectives, as well as the preparations for human exploration that are encapsulated in the MEPAG Goals Document. By utilizing missions in all size classes, in addition to Mars Sample Return, such a Mars program could provide feed-forward on both science and technology development, coordination across missions to achieve the science objectives, coordination with international and corporate partners, and coordination with HEOMD to ensure that objectives necessary to support humans can be attained. The key is to match mission classes to science objectives, spanning the range from small spacecraft up through at least New-Frontiers-class missions. However, technology development will be needed to enable a wider variety of lower-cost mission architectures to access the surface, especially in cases where lateral mobility is required.

\section{CONCLUSION}

Mars is one of the most scientifically compelling planetary bodies in the Solar System, where NASA has regular opportunities to launch missions on short trajectories every 26 months with complex and highly sophisticated instrumentation. The MEPAG Goals Document synthesizes the community's scientific objectives to be carried out by and in support of the robotic Mars flight program as well as the important steps needed to prepare for human exploration. The main conclusions of this white paper are as follows:

1. The breadth of science identified in the MEPAG Goals Document captures the richness to be gained by more fully exploring Mars.

2. Mars as a target teaches us not only about the one planet, but terrestrial planets (including exoplanets) as a class.

3. Mars is the closest and most easily accessed place where life may have originated outside of Earth.

4. A vigorous program of Mars exploration, as part of a robust, balanced solar system exploration strategy is warranted by the preceding three points.

5. Important advances on the science Goals identified in the MEPAG Goals Document can be attained by mission architectures ranging from Mars sample return all the way down to SmallSats, cubesats and miniature landers.

\section{$\underline{\text { References }}$}

MEPAG (2020), Mars Scientific Goals, Objectives, Investigations, and Priorities: 2020. D. Banfield, ed., 89 p. white paper posted March, 2020 by the Mars Exploration Program Analysis Group (MEPAG) at https://mepag.jpl.nasa.gov/reports.cfm. 